\title{
Psychomotor learning theory informing the design and evaluation of an interactive augmented reality hand hygiene training app for healthcare workers
}

\author{
Gerard Lacey $^{1,2,3}$ (D) Lucyna Gozdzielewska ${ }^{4}$ (D) . \\ Kareena McAloney-Kocaman ${ }^{5}$ (D) Jonathan Ruttle ${ }^{2}$. Sean Cronin ${ }^{1,2}$ (D) \\ Lesley Price $^{4}$ iD
}

Received: 12 May 2021 / Accepted: 19 September 2021/ Published online: 11 October 2021

(c) The Author(s) 2021

\begin{abstract}
Hand hygiene is critical for infection control, but studies report poor transfer from training to practice. Hand hygiene training in hospitals typically involves one classroom session per year, but psychomotor skills require repetition and feedback for retention. We describe the design and independent evaluation of a mobile interactive augmented reality training tool for the World Health Organisation (WHO) hand hygiene technique. The design was based on a detailed analysis of the underlying educational theory relating to psychomotor skills learning. During the evaluation forty-seven subjects used AR hand hygiene training over 4 weeks. Hand hygiene proficiency was assessed at weekly intervals, both electronically and via human inspection. Thirty eight participants $(81 \%)$ reached proficiency after 24.3 $(\mathrm{SD}=17.8)$ two-minute practice sessions. The study demonstrated that interactive mobile applications could empower learners to develop hand hygiene skills independently. Healthcare organizations could improve hand hygiene quality by using self-directed skills-based training combined with regular ward-based assessments.
\end{abstract}

Keywords Mobile augmented reality · Mobile learning · Psychomotor learning · Deliberate practice $\cdot$ Test enhanced learning $\cdot$ Hand hygiene training

Gerard Lacey

Gerard.Lacey@mu.ie

1 School of Computer Science \& Statistics, Trinity College Dublin, Dublin 2, Ireland

2 SureWash, Dublin, Ireland

3 Department of Electronic Engineering, Maynooth University, Maynooth, Co. Kildare, Ireland

4 Department of Nursing and Community Health, Glasgow Caledonian University, Glasgow, Scotland

5 Applied Health Psychology at Glasgow Caledonian University, Glasgow, Scotland 


\section{Problem definition}

Hand hygiene is critical for patient safety (Allegranzi \& Pittet, 2009). The World Health Organisation (WHO) provides guidelines on when and how to perform hand hygiene (WHO, 2009); these are the "5 moments of hand hygiene" and the "WHO 6-step technique". The need for training in hand hygiene is well established. Studies have shown a 50\% improvement in the effectiveness of alcohol following training (Widmer et al., 2007). Repeated hand hygiene training also improves hand hygiene effectiveness (Sutter et al., 2010). However, current training approaches typically involve one-off annual classes with no opportunity to attain or demonstrate proficiency. Consequently, the hand hygiene technique is not well retained, with audits showing that only $8 \%$ of healthcare workers use the WHO technique in clinical practice (Tschudin-Sutter et al., 2015).

Clinical skills such as suturing, catheter insertion or intubation are trained in skills labs and assessed by demonstrating proficiency to trained assessors as part of an Objective Structured Clinical Exam (OSCE) (Turner \& Dankoski, 2008). Despite its critical role in patient safety, hand hygiene is not currently trained or assessed in an OSCE. However, quality assurance in healthcare is beginning to require "competency validation" in hand hygiene (AAPACN, 2020; CMS, 2019; SA_Health, 2020).

\section{Educational theories relevant to hand hygiene training}

This section reviews pedagogical models relevant to training physical skills and examines their implications for designing a hand hygiene training programme. Clinical skills have been traditionally taught in healthcare using a "see one, do one, teach one" approach, but it was clear that more effective methods were required (McLeod et al., 2001). We will focus on three inter-related concepts to training psychomotor skills: Deliberate Practice, Mastery Learning and Test Enhanced Learning. We will discuss Overlearning and its role in the retention of skills. We will also summarise other factors related to how training is delivered, i.e., cognitive load, the distribution of training episodes, the transfer of learning into practice and skills decay. We will build on the framework outlined in (Kardong-Edgren et al., 2019) to develop a set of instructional design principles for our mobile Augmented Reality (AR) training tool for hand hygiene.

Ericsson (2008) proposes that expert performance is not achieved by experience alone but through a focused and deliberate engagement with improving professional practice. His "Deliberate Practice" method's two key features are skills improvement following immediate feedback from a coach and repeated practice with feedback to further refine performance. Time spent in practice does not necessarily improve skill as Deliberate Practice is a cognitively demanding activity for students, especially for novices (Rikers et al., 2004). Deliberate Practice with formative assessment has improved psychomotor skills in ultrasound (Schott et al., 2020) and helped develop expert performance in fields as diverse as music, sports and surgery. 
The well-known educational psychologist B.S. Bloom developed Mastery Learning (Block \& Burns, 1976) (Bloom, 1984). It posits that each student develops skills at a different rate and that learning is divided into incremental units, each with an associated assessment. Students should progress to the next unit only after demonstrating Mastery of the preceding unit. The positive results reported from Deliberate Practice and Mastery Learning may also be benefiting from Test Enhanced Learning (Carrier \& Pashler, 1992; Roediger \& Karpicke, 2006). These studies demonstrated that testing rather than repetition significantly enhanced retention, which also applies to psychomotor skills (Kromann et al., 2009). The hypothesis is that testing promotes more active learning, which has been shown in online video instruction, where frequent tests and formative assessments promote more active learning (Brame, 2016).

Deliberate Practice, Mastery Learning and Test Enhanced Learning are complementary and often overlap. In a review of "flipped classroom" models for healthcare education, (Persky \& McLaughlin, 2017) support a Mastery Model involving baseline testing, multiple units with clear assessment objectives and units sequenced in increasing difficulty. Deliberate Practice within each unit focused on corrective coaching for errors central to the demonstration of expertise. The repeated testing of skills with Mastery Learning and Deliberate Practice delivers the enhanced recall produced in Test Enhanced Learning.

Overlearning is practising a skill after Mastery is achieved and significantly improves retention (Driskell et al., 1992). The amount of Overlearning needed to demonstrate improvement is related to the number of attempts it took to achieve Mastery, e.g. if it took ten attempts to achieve Mastery, then 50\% Overlearning would correspond to five further training sessions. The effect of Overlearning was most significant between 50 and $100 \%$, but performance continued to improve by $200 \%$. The natural impact of skills decay limits the benefits of overtraining on retention, and refresher training is recommended at an interval of 3-6 weeks. However, in an extensive study of 20,000 army reservists (Wisher, 1992), most skills had decayed within six months, but psychomotor skills lasted ten months. For hand hygiene training, this suggests that refresher training should occur every 6 to 12 months and that students continue to be assessed after initial proficiency is achieved.

Managing the cognitive load for students as they progress through the learning units is a crucial issue and the 4 stage "conscious-competence" framework (Fig. 1), developed initially by Noel Burch in the 1970s (Cannon et al., 2014), provides a conceptual framework for the learning journey. In the Unconscious Incompetence phase, the student is unaware of their lack of competence and attempt to solve problems using intuition with no insight into the underlying principles. Students recognise shortcomings in the Conscious Incompetence phase but have not acquired the skills to produce the desired outcome. Students can achieve the desired result in the Conscious Competence phase, but the skills are not yet automated, i.e. demonstrated without conscious thought. In the Unconscious Competence phase, demonstrating the skills does not require much cognitive load. The framework also integrates the notion of skill decay by incorporating the need to perform regular top-up training to maintain skill levels.

Mayer and Moreno (2003) examine the issue of cognitive load in the context of multi-media instruction and propose several approaches to mitigate the load on 
Fig. 1 The conscious competence framework ( copyright with authors)

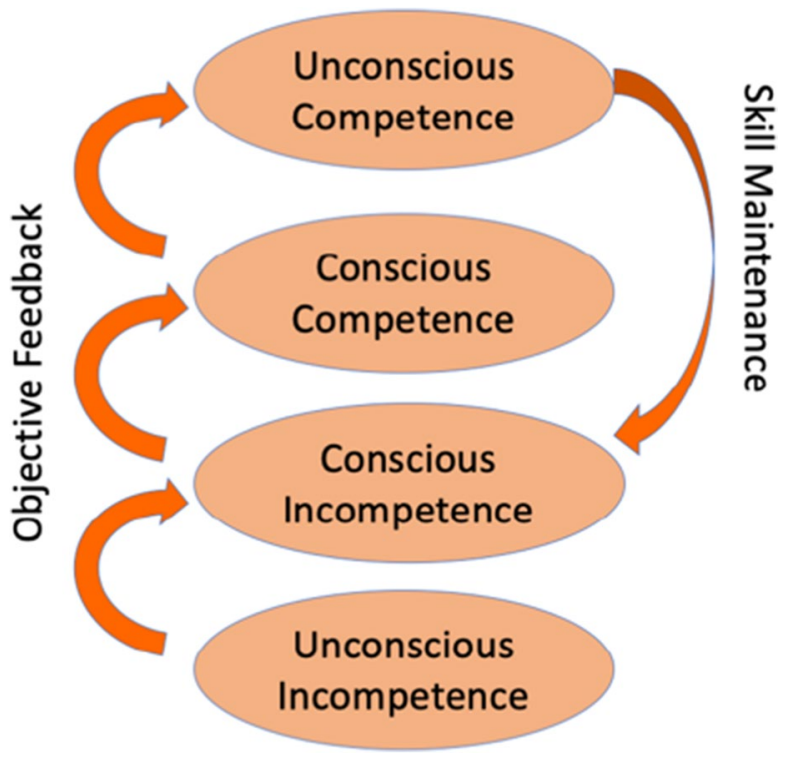

students: providing pre-training in the concepts to be practised, presenting information using multiple sensory modes, allowing the learner to pause when overloaded, eliminating all extraneous information until the students have a framework to process this material and eliminating redundancy in visual and auditory information. When developing procedural skills, it is best to allow students to practice the finegrained steps (Jannin et al., 2019). This "action atomisation" approach helps manage the cognitive load, and repeated fine-grained practice helps skills acquisition.

The schedule of learning opportunities has a significant impact on learning and retention. Distributed training, i.e. multiple short sessions distributed over time, has better outcomes than massed training, i.e. a single long training session (Mackay et al., 2002; Moulton et al., 2006). fMRI studies (Karni et al., 1998) have shown that this effect correlates with the underlying neuroscience and relates to 3 types of learning: "fast" learning that happens within a session, the consolidation of learning that happens $6-8 \mathrm{~h}$ after training and is aided by sleep (Fischer et al., 2002) and then "slow" incremental learning that occurs with repeated practice. The implications for psychomotor skills training are that students need to acquire, consolidate and refine motor skills over 3 weeks.

In vocational training, a key learning outcome is a transfer of training to practice within the workplace. Multiple studies (Blume et al., 2009; Tonhäuser \& Büker, 2016) find that learning transfer is influenced by intrinsic learner motivation and peer and supervisor support. The training design implications are that training has practical relevance and that post-training follow-up is provided to maintain the new skills.

(Kardong-Edgren et al., 2019) explore the theories relevant to psychomotor skills training as applied to nursing and its relevance to simulation-based learning. We have adapted their framework to the design of a hand hygiene training programme shown in Table 1. 


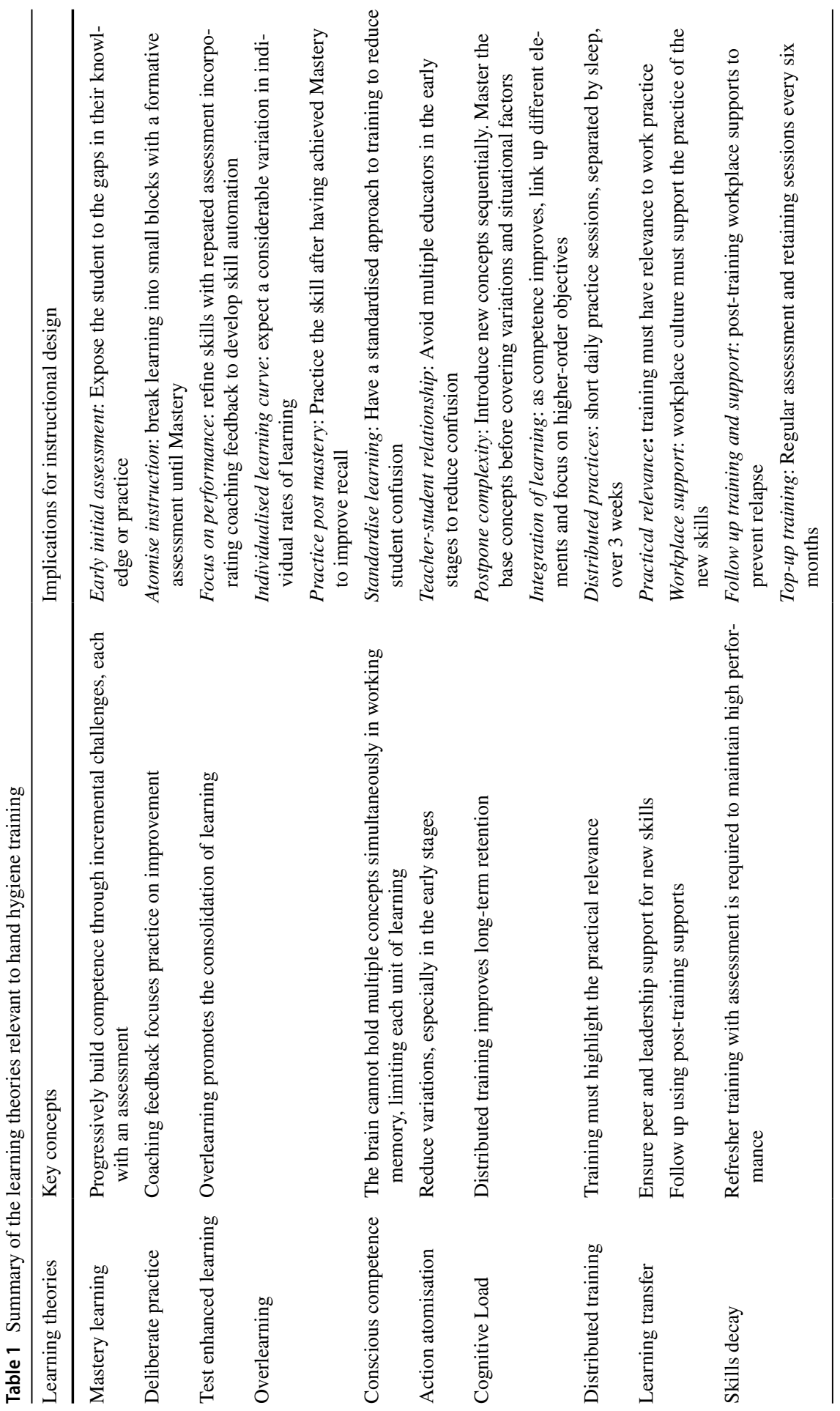




\section{Interactive augmented reality training tools for psychomotor skills}

AR training tools have been applied to spatial and psychomotor skills training in both medical and non-medical domains. The real-time feedback from AR scaffolds the development of skills while interacting with the materials. In so doing, it naturally supports Experiential Learning (Kolb, 1981), and the scaffolding aligns with the conscious competence model (Cannon et al., 2014) and Vygotsky's zone of proximal development (Harland, 2003).

In reviewing the literature, $51 \%$ of the AR training tools in the literature were developed for K-12 education (Akçayır \& Akçayır, 2017). While the majority of studies report positive learning outcomes, there are also challenges. For example, AR did not produce better learning outcomes on a spatial visualisation task, but it did reduce students' cognitive load (Slijepcevic, 2013). This result may be because the use of AR content can implicitly result in better "atomisation of instruction" (Jannin et al., 2019).

AR has demonstrated specific relevance for spatial learning such as dance or other complex movements as it allows users to verify their learning outcomes while practising resulting in significantly accelerated learning compared with video instruction (Anderson et al., 2013). AR also produced better learning outcomes in physical education than video instruction, with more substantial effects for more complex movements (Chang et al., 2019). AR has also been applied to learning complex tools in welding (Okimoto et al., 2015), calligraphy (Limbu et al., 2018), construction safety (Le et al., 2015) and musical education (Marky et al., 2019).

Virtual and AR simulators are used extensively in medical education. Kneebone (Kneebone et al., 2004) discusses the iterative relationship between simulation training and clinical practice to support learners through different learning phases. Multiple studies have demonstrated similar iterative approaches (Khan et al., 2019; Mladenovic et al., 2019; Reed et al., 2016; Salem et al., 2020). However, several reviews of AR (Chytas et al., 2019; Gerup et al., 2020; Zhu et al., 2014) report that most systems are early prototypes, and few use an underlying learning theory.

\section{Previous designs of AR hand hygiene training systems}

AR for hand hygiene training has been evaluated as a wall-mounted "edge-AI" system (Ghosh et al., 2013; Lacey et al., 2020) which was mounted over a wash hand basin. The camera points vertically downwards, taking a video image of the user's hands. The system aimed to assist the user to comply with the WHO hand hygiene guidelines shown in Fig. 2. The Augmented Reality (AR) component of the system consists of real-time graphical feedback overlaid on the video of the users hands that responds to the users hand motions. In the over wash hand basin system, a single screen showed all the poses in a reg/green traffic light system indicated to the user when they had completed each pose, as shown in Fig. 3. This system worked as both a monitoring and a tutoring system. Because of its monitoring role, the user was able to complete the poses in any order. 


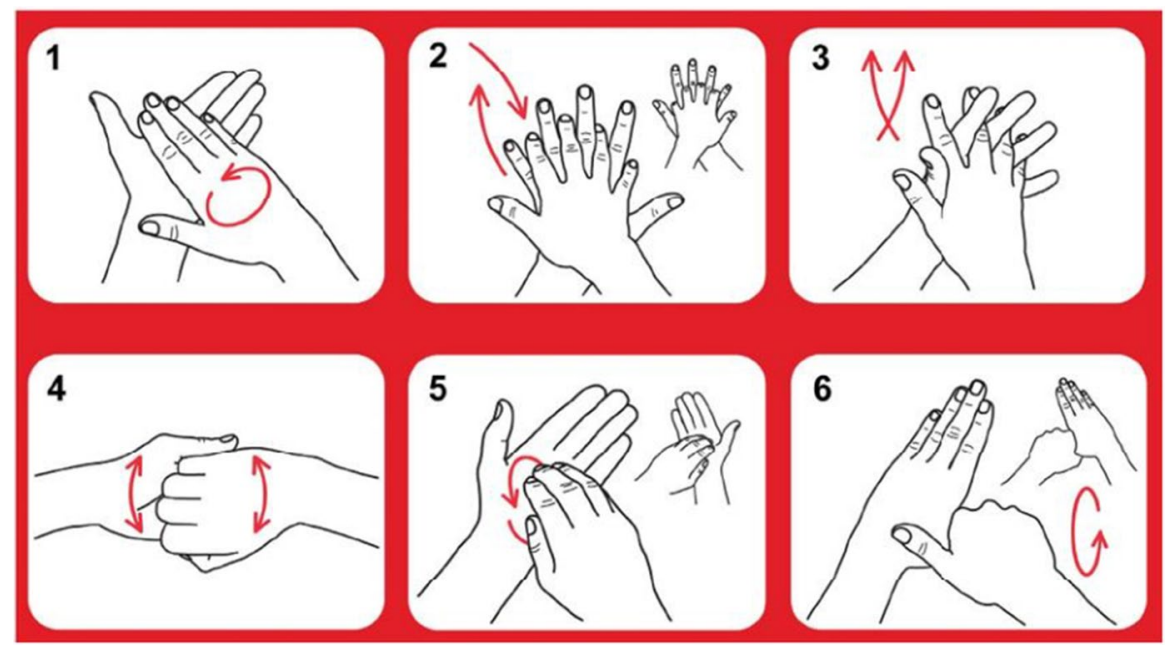

Fig. 2 The World Health Organisation (WHO) 6 poses for effective hand hygiene- copyright WHO (CC BY 4.0)

SureWash then developed a cart-based AR training kiosk (Higgins and Higgins 2013) (Stewardson et al., 2014). With the monitoring function removed, the focus of the user's experience was now explicitly hand hygiene training. The educational focus allowed poses to be trained separately and in the order that they appear within the WHO guidelines. The cart-based system is shown in Fig. 4. The AR elements were enhanced with progress bars that respond to the user's movement and demonstration videos that pop up of the user is having difficulty. Initially, there were two levels: a scaffolded training mode and an assessment mode that did not provide prompts. The educational set-up was that users could repeat the training mode as many times as they liked and then pass the assessment mode.

Fig. 3 Original feedback screen of the SureWash system ( copyright with authors)

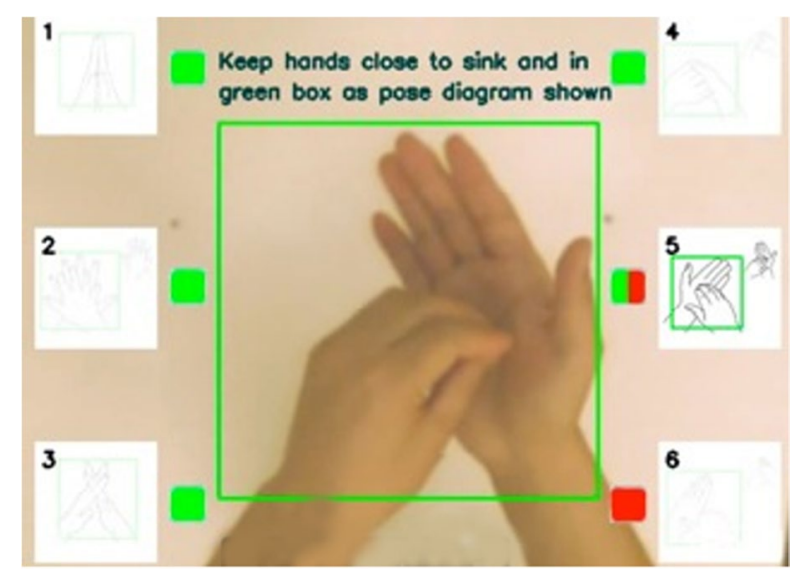


Fig. 4 SureWash as a cart-based training kiosk ( copyright with authors)

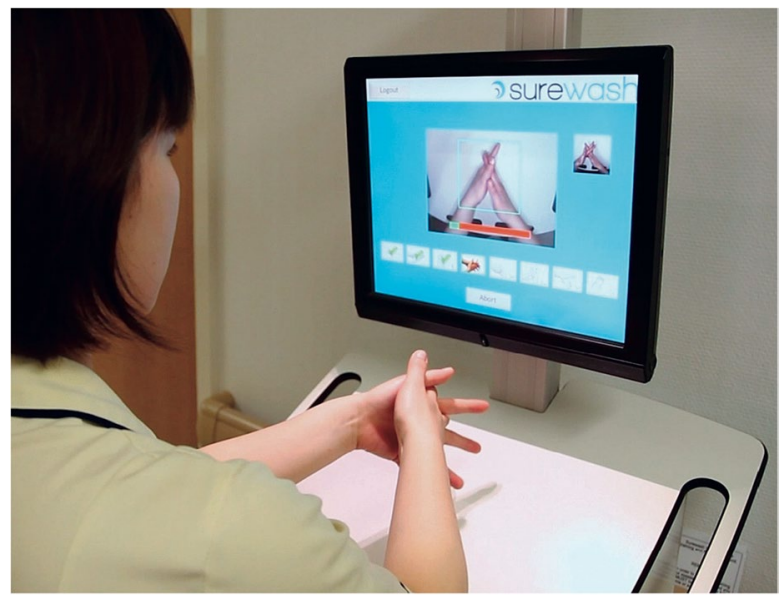

A more portable version of the system was developed that can be desk or wallmounted, as shown in Fig. 5. This system was the first to use the more explicit scaffolding approach as indicated in the educational theories outlined in a previous section by breaking competence development into five levels (Lacey et al., 2019).

\section{Developing a mobile phone AR hand hygiene training system}

This study describes the first attempt to deliver AR hand hygiene training on a personal mobile device. Our objective was to support hand hygiene training at any time or place, thus enabling patients and families to access interactive hand hygiene training.

The initial challenge was that a camera pointing vertically down at the users' hands was impossible using a mobile phone. As shown in Fig. 6, our approach used the frontfacing "selfie camera" to track the user's hand motions. The phone is placed on a table, and the hand hygiene motions are practised $50 \mathrm{~cm}$ above the phone. The computer vision algorithms developed for the over the sink system (Llorca et al., 2007) were modified to allow the bottom-up rather than the top-down presentation of the hands.

The user can see the screen as they perform the hand hygiene motions, and they are shown a live video of their hands. The AR elements of the system, shown in Fig. 7, are as follows: the progress bars have been changed to be on the left and right of the video image and move from bottom to top as the user correctly preforms each pose. The bars move simultaneously when a step does not have separate left and right hands parts, e.g. palm-to-palm. The green box overlaid on screen indicates that the user's hands are in the correct zone. When the user's hands drift out of the zone the box it turns read. The image outside of the green box is slightly blurred to subtly guide the user toward the centre of the camera field of view.

The instruction is provided in 5 Levels of difficulty. In contrast to earlier work, each level has a specific user goal and increasing difficulty level. The goal for the level is shown at the bottom of the screen e.g. in Fig. 7 "Remaining Time: 1 s". 


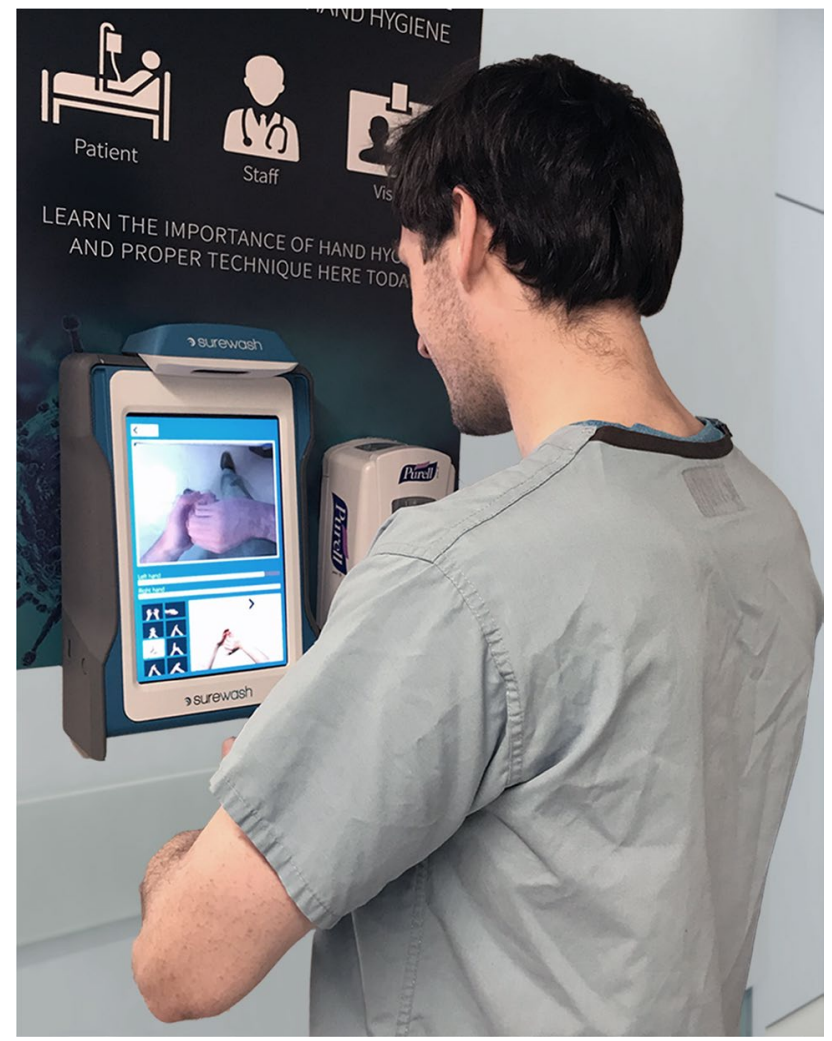

Fig. 5 SureWash Go system that incorporates the five levels with horizontal progress bars ( copyright with Authors)

Levels 1-4 incorporated formative assessment that progressively built the user's competence and are described in detail below. Level 5 provides the summative assessment for proficiency in hand hygiene.

Fig. 6 SureWash App running on a phone placed on the table. The front-facing "selfie" camera tracks the user's hands

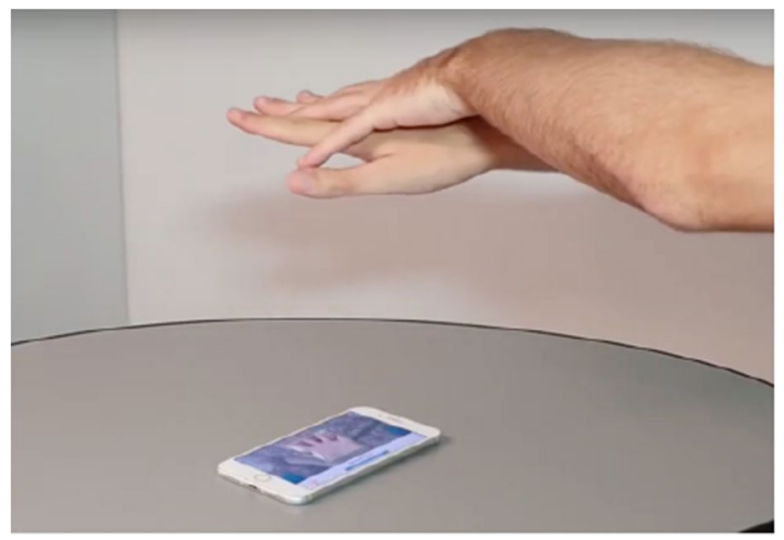




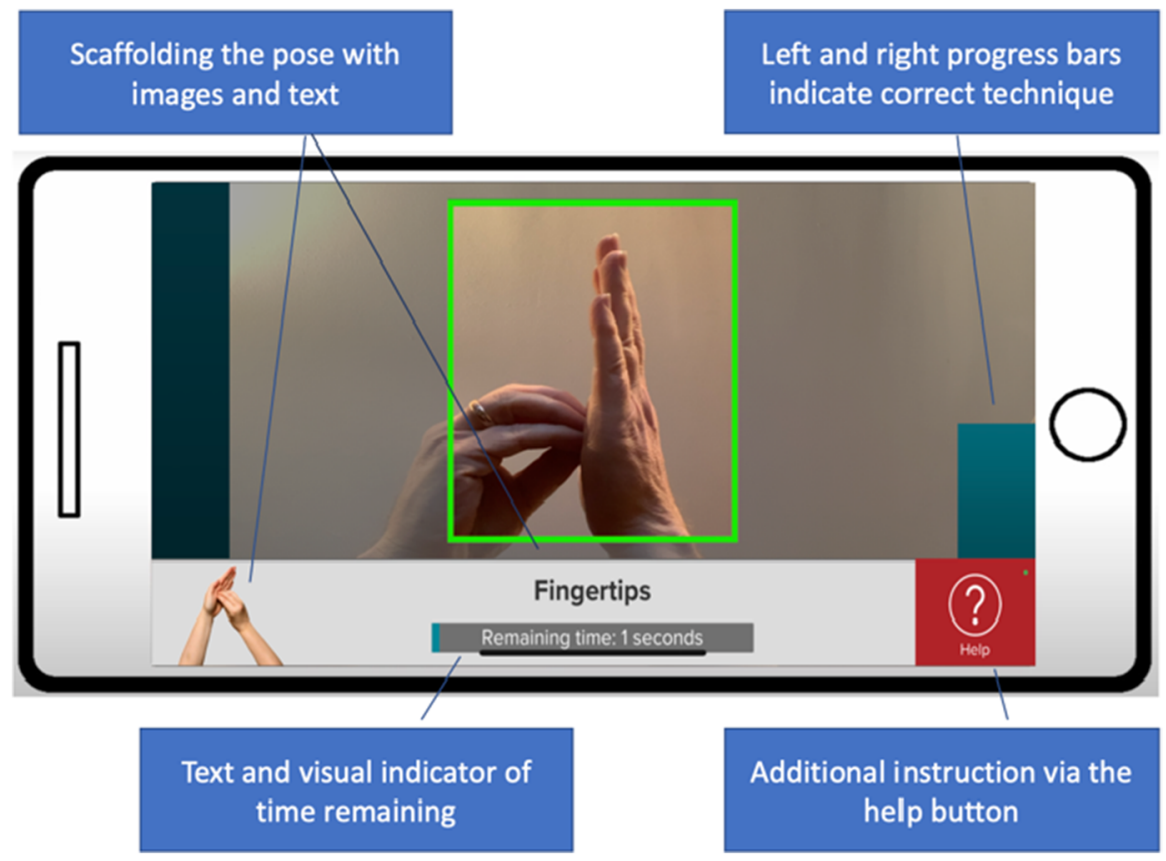

Fig. 7 Typical user feedback in Level 3, scaffolding via image and test prompting with additional instruction via the help button. Feedback on progress via left and right progress bars and a time remaining indicator. ( copyright with authors)

Level 1 Provides separate instruction on each of the six poses. Video instruction is followed by AR assessment. Early assessment aligns with the conscious competence model and breaking the instruction down to fundamental components aligns with the concept of atomised instruction. We supported the Mastery model of instruction by unlocking Level 2 only after the student had achieved the required standard on Level 1.

Level 2 Integrates the individual poses into a "smooth flow" of hand hygiene. Scaffolding is reduced to an icon to remind the learners of the current pose. If the learner is struggling, there is a help button that will give step specific additional instructions. There is no time limit in Level 2.

Level 3 Focuses on refining hand hygiene performance with a game like challenge of a 40 second time limit. The help button was removed, but image and text prompts were retained.

Level 4 Further refined performance by reducing the time limit to 30 seconds, and Level 3 scaffolding was retained.

\section{Level 5}

Is a delayed recall test. All scaffolding was removed, and the learners must correctly demonstrate the hand hygiene poses and complete the sequence in under $30 \mathrm{~s}$. 
The mobile app can be linked with a Virtual Learning Environment such as Canvas, Blackboard or Moodle to allow the Instructor to configure aspects of the training such as the number of repetitions required for each level, i.e., the amount of overtraining required. Training results from each of the learners were sent to a cloud learning management system. For the study's purposes, each participant was provided with an anonymised login, and the blinded results were delivered to the independent assessment team. The hand hygiene app is free to download (SureWash, 2021).

\section{Independent evaluation of the mobile app}

The mobile AR hand hygiene training app was evaluated in a prospective cohort study conducted by an independent research team at Glasgow Caledonian University (GCU). This study aimed to investigate the duration of deliberate practice training required for the development of proficiency in performing the World Health Organization's 6-step hand hygiene technique, with consideration of the following research questions:

- How many deliberate practice training sessions are required to develop proficiency in the 6-step technique for hand hygiene?

-Is there a difference in the number of deliberate practice training sessions required to develop proficiency of the 6-step technique for hand hygiene between participants from different age groups?

-Is there a difference in the number of deliberate practice training sessions required to develop proficiency of the 6-step technique for hand hygiene between male and female participants?

-Is there a difference in the number of deliberate practice training sessions required to develop proficiency of the 6-step technique for hand hygiene between participants who received previous hand hygiene training and participants who did not?

-Does the level of manual dexterity influence the number of deliberate practice training sessions required to develop proficiency of the 6-step technique for hand hygiene?

\subsection{Data collection}

Participants were asked to download the AR hand hygiene training app to their own mobile devices, log in using the randomly assigned credentials and practice the 6-step hand hygiene technique daily using the mobile app. Training required approximately one minute per day and could be done at a time and place convenient to the participant. The level of training complexity was, to a certain extent, controlled by the participants. Supporting the Mastery model of instruction, each level of difficulty, apart from the most basic level 1, became unlocked after the participant achieved the preceding level. However, participants were instructed 
to progress to the next, unlocked level when they felt ready to do so. Participants received immediate feedback on their performance following each training episode. Data collection occurred between the 22nd of June and the 1st of October 2018.

\subsection{Measures}

At baseline, participants' ability to acquire manual skills was assessed using the Purdue Pegboard manual dexterity test (Tiffin, 1968; Tiffin \& Asher, 1948; Tseng et al., 2017). In summary, the test involved placing as many pegs as possible into a pegboard for $30 \mathrm{~s}$ using: (1) dominant hand, (2) non-dominant hand (3) both hands simultaneously, and (4) assembling units of pegs, washers and collars for one minute using both hands. Manual dexterity combined score was calculated by summing the number of pins inserted by left (test 1) and right hand (test 2) and the number of pairs of pins inserted by both hands during test 3 , while a manual dexterity assessment score was determined by counting the number of parts assembled during test 4 (Mylon et al., 2016). Each participants' manual dexterity scores were recorded on a standardised data collection form along with the participant's gender, age, dominant hand and previous training experience.

At the end of each week, participants were seen individually by a member of the GCU research team to identify any difficulties and to assess their level of proficiency using a validated SureWash® ELITE system (Stewardson et al., 2014). Participants logged into the system using the same login details as they used for the app. In the current study, participants' performance was assessed at level 5 (competence and time-based skill level with no prompts). To pass the assessment, participants were required to correctly perform all six steps of the 6-step hand hygiene technique in the correct order in 20-30 s, as per WHO hand hygiene guidelines (WHO, 2009). Passing this level was considered to be indicative of having achieved proficiency. At the same time, participants' performance was visually observed by a single, trained researcher and documented on a standard data collection sheet.

Data from the SureWash Elite, on whether or not participants achieved a pass at level 5/proficiency, and data from the app. on frequency and timing of the app use and level of difficulty at which practice had occurred, were stored on a cloud learning management system managed by SureWash. These data were provided to the GCU research team in anonymised form at the end of the 4-week period of data collection.

\subsection{Data analysis}

The number of training sessions required to achieve proficiency in performing the 6-step technique was analysed descriptively. The relationship between the number of training sessions needed to achieve proficiency and participants' characteristics and manual dexterity scores were investigated using t-test and correlation. Anonymised data from the app on the number of training sessions were analysed descriptively to determine participants' engagement with daily practice. The Chi-square test was used to compare the proportion of participants who practised each week and passed 
the assessment with those who did not practice. Finally, patterns of participants' weekly performance, assessed at both visual inspection and automated assessment, were analysed descriptively. Chi-square was performed to compare automated and visual proficiency pass ratings for each week assessment. A p-value of $p<0.05$ was considered to be statistically significant.

\section{Results}

Amongst the 47 study participants, most were female $(n=36,77 \%)$, right-handed $(\mathrm{n}=45,96 \%)$ with previous hand hygiene training experience $(\mathrm{n}=30,64 \%)$. The mean age was 42.6 years $(24-61)$.

Proficiency in performing the correct 6-step hand hygiene technique, as assessed by the SureWash ELITE system, was achieved by 38 participants (81\%), with the mean number of $24.3(\mathrm{SD}=17.8)$ training sessions required to achieve proficiency. Results of the independent samples t-test presented in Table 2 showed that males required significantly fewer training sessions to achieve proficiency in comparison with females $(\mathrm{t}=-2.91 ; \mathrm{df}=35.9 ; \mathrm{p}=0.006)$. Participants' previous hand hygiene training experience and handedness did not significantly affect the number of practice sessions required to achieve proficiency. Furthermore, as indicated by the correlation analysis (Pearson's), no significant relationship was found between the number of practice sessions required to achieve proficiency and participants' age $(\mathrm{r}=0.115, \mathrm{p}=0.491)$, manual dexterity combined score $(\mathrm{r}=0.051 ; \mathrm{p}=0.760)$ or manual dexterity assessment score $(r=-0.022 ; p=0.894)$.

Participants' engagement with everyday practice of the 6-step technique using the app and the overall mean number of practice sessions declined after the first week (Table 3).

Furthermore, as shown in Table 4, there was no significant difference in the weekly assessment pass rates between those who practised hand hygiene and those who did not in the first $\left(\chi_{(47)}^{2}=0.74 ; p=0.391\right)$, second $\left(\chi_{(42)}^{2}=0.003 ; p=0.955\right)$ and third week $\left(\chi_{(42)}^{2}=0.036 ; \mathrm{p}=0.849\right)$. However, while none of the participants who practised in week four also passed the week four assessment, $49 \%$ of those who had not practised this week demonstrated proficiency at the assessment. This difference was significant $\left(\chi_{(40)}^{2}=5.657 ; \mathrm{p}=0.017\right)$.

\subsection{Proficiency assessment agreement between automate and visual proficiency assessment}

Proficiency measured using the SureWash ELITE system was compared with proficiency assessed using direct, visual observation. Descriptive results presented in Table 5 show that visual observation resulted in greater pass rates for all weeks than those assessed using the automated system. Analysis of the patterns of participants' performance showed that while only two participants (4\%) passed all four automated proficiency assessments, 15 (32\%) passed all visual assessments. Furthermore, 
Table 2 Relationship between the number of training sessions required to achieve proficiency and participants' characteristics

\begin{tabular}{|c|c|c|c|}
\hline Characteristic variable & $\mathrm{N}$ & $\begin{array}{l}\text { Median number of sessions required to } \\
\text { achieve proficiency (SD) }\end{array}$ & Sig \\
\hline \multicolumn{4}{|l|}{ Gender $^{\mathrm{a}}$} \\
\hline Male & 10 & $15.3(6.34)$ & \multirow[t]{2}{*}{$0.006^{*}$} \\
\hline Female & 28 & $27.8(19.45)$ & \\
\hline \multicolumn{4}{|l|}{ Previous training ${ }^{\mathrm{a}}$} \\
\hline Yes & 28 & $23.4(16.87)$ & \multirow[t]{2}{*}{0.609} \\
\hline No & 10 & $26.8(20.82)$ & \\
\hline \multicolumn{4}{|l|}{ Handedness $^{\mathrm{a}}$} \\
\hline Right-handed & 36 & $23.2(17.30)$ & \multirow[t]{2}{*}{0.117} \\
\hline Left-handed & 2 & $43.5(20.51)$ & \\
\hline Manual Dexterity combined score ${ }^{b}$ & & Not applicable & 0.760 \\
\hline Manual Dexterity assessment score ${ }^{b}$ & & Not applicable & 0.894 \\
\hline $\mathrm{Age}^{\mathrm{b}}$ & & Not applicable & 0.491 \\
\hline
\end{tabular}

*Statistically significant difference at $\mathrm{p}<0.05$

${ }^{a}$ Independent sample t-test

${ }^{\mathrm{b}}$ Pearson correlation

Table 3 Fidelity to study design

\begin{tabular}{llll}
\hline Week number & $\begin{array}{l}\mathrm{N}(\%) \text { of participants who } \\
\text { practised daily with the app }\end{array}$ & $\begin{array}{l}\mathrm{N}(\%) \text { of participants who practised } \\
\text { immediately before the assessment }\end{array}$ & $\begin{array}{l}\text { Mean number of } \\
\text { practice sessions } \\
\text { (SD) }\end{array}$ \\
\hline Week 1 & $13(28 \%)$ & $21(45 \%)$ & $18.3(18.3)$ \\
Week 2 & $4(10 \%)$ & $19(48 \%)$ & $12.1(13.5)$ \\
Week 3 & $8(19 \%)$ & $14(35 \%)$ & $7.6(10.5)$ \\
Week 4 & $7(18 \%)$ & $10(26 \%)$ & $6.6(12.0)$ \\
\hline
\end{tabular}

Table 4 Comparison of weekly pass rates between those who practised the 6-step technique using the mobile app and those who did not

\begin{tabular}{|c|c|c|c|}
\hline \multirow[t]{2}{*}{ Week number } & \multicolumn{2}{|c|}{$\begin{array}{l}\mathrm{N}(\%) \text { of participants who passed weekly assessment using the } \\
\text { automated system }\end{array}$} & \multirow[t]{2}{*}{ Sig } \\
\hline & Participants who practised & $\begin{array}{l}\text { Participants who did not } \\
\text { practice }\end{array}$ & \\
\hline Week 1 & 1 out of $13(8 \%)$ & 6 out of $34(18 \%)$ & 0.901 \\
\hline Week 2 & 1 out of $4(25 \%)$ & 10 out of $38(26 \%)$ & 0.955 \\
\hline Week 3 & 3 out of $8(38 \%)$ & 14 out of $34(41 \%)$ & 0.849 \\
\hline Week 4 & 0 out of $7(0 \%)$ & 16 out of $33(49 \%)$ & $0.017 *$ \\
\hline
\end{tabular}

*Statistically significant difference at $\mathrm{p}<0.05$ 
Table 5 Comparison of automated and visual assessment findings

\begin{tabular}{llllll}
\hline $\begin{array}{l}\text { Week } \\
\text { number }\end{array}$ & $\begin{array}{l}\text { N (\%) of } \\
\text { participants who } \\
\text { passed the weekly } \\
\text { assessment using } \\
\text { the automated } \\
\text { system }\end{array}$ & $\begin{array}{l}\text { N }(\%) \text { of } \\
\text { participants } \\
\text { weekly visual } \\
\text { assessment }\end{array}$ & $\begin{array}{l}\text { N (\%) of participants } \\
\text { who passed auto- } \\
\text { mated assessment } \\
\text { \& passed visual } \\
\text { inspection }\end{array}$ & $\begin{array}{l}\text { N (\%) of participants } \\
\text { who failed automated } \\
\text { assessment \& passed } \\
\text { visual inspection }\end{array}$ & Sig \\
\hline Week 1 & $7(15 \%)$ & $20(47 \%)$ & $5(100 \%)$ & $15(40 \%)$ & $0.011^{*}$ \\
Week 2 & $11(26 \%)$ & $33(72 \%)$ & $12(100 \%)$ & $21(62 \%)$ & $0.011^{*}$ \\
Week 3 & $17(41 \%)$ & $39(89 \%)$ & $16(100 \%)$ & $23(82 \%)$ & $0.073 * *$ \\
Week 4 & $16(40 \%)$ & $35(90 \%)$ & $15(100 \%)$ & $20(83 \%)$ & $0.095^{* *}$ \\
\hline
\end{tabular}

* Statistically significant difference at $\mathrm{p}<0.05, * *$ breached the assumptions of the chi-square test

based on the automated system, 17 participants (36\%) passed an assessment on week 1 but failed all follow-up assessments, 6 participants (13\%) failed week 1 assessment but passed at least two consecutive later assessments, five participants (11\%) only passed assessment 4, while 17 participants (36\%) failed all assessments. In comparison, when the researcher visually observed participants, seven (15\%) of them passed an early assessment week one but failed all follow-up assessments, 21 (45\%) failed an early assessment but passed at least two consecutive follow-ups, one (2\%) only passed assessment 4, and only three participants (6\%) failed all four assessments.

Interestingly, all participants who passed the assessment using the automated system also passed the assessment by the means of direct, visual observation (Table 5). However, a chi-square test indicated that there was a significant difference between the percentage of participants who failed automated assessment and passed visual inspection at week one $\left(\chi^{2}{ }_{(43)}=6.507 ; \mathrm{df}=1 ; \mathrm{p}=0.011\right)$ and week two $\left(\chi_{(46)}^{2}=6.396 ; p=0.011\right)$. No significant difference was observed between the percentage of participants who failed automated assessment and passed visual inspection at week $3\left(\chi_{(44)}^{2}=3.223 ; p=0.073\right)$ and week $4\left(\chi_{(39)}^{2}=2.786 ; p=0.095\right)$.

\section{Discussion and conclusions}

This study sought to address the low retention of the WHO hand hygiene technique among healthcare workers (HCW). We analysed the current pedagogical approach of annual classroom sessions. We found that it did not conform with the theories of psychomotor skill development required to develop proficiency in the WHO hand hygiene technique. We adapted an existing AR training tool and pedagogical model to be delivered via a mobile app. The app supported daily self-directed hand hygiene training by the HCW that aligns with a Deliberate Practice pedagogy. We then performed an independent evaluation of the hand hygiene training programme in the Department of Nursing and Community Health at GCU. The study was limited to 47 voluntary participants and did not have a control group. This arm of the study developed an effective 2 stage teaching model of independent learning plus validated competence demonstration inspired by the underlying learning theory. 
The first significant finding is that 38 participants $(81 \%)$ required a mean number of $24.3(\mathrm{SD}=17.8)$ training sessions to achieve proficiency. This result highlights that the one-off classroom sessions are inappropriate for developing proficiency in hand hygiene and that deliberate practice is a more effective pedagogical model.

The study design had both visual assessment and automated assessment. A single experimenter conducted the visual assessment and consistently passed more subjects than the automated system. One limitation is that there was no second human evaluator, so it was impossible to calculate the visual assessment's interrater reliability. The difference between visual and automated assessment was significant only for the first 2 weeks and may have been due to participants getting used to the automated assessment.

The study found that males reached proficiency faster, after 15.3 sessions, whereas females took 27.8 sessions. None of the other factors such as age, handedness, manual dexterity or prior training were significant. Previous studies of developing hand hygiene proficiency (Lacey et al., 2019) had 42 subjects but showed no gender difference. Some studies of suturing skills suggest that females can learn dexterous skills faster (Chiu et al., 2020), so it will be interesting to see if this finding persists in future more extensive studies.

The study design involved volunteers in a university setting; most hand hygiene training is provided as compulsory occupational safety training in healthcare settings. Further studies are required to assess if the healthcare setting and compulsory learning significantly impact the results.

In-depth analysis of app usage showed that daily practice was low, varying from a low of $10 \%$ to a high of $28 \%$ over the 4 weeks of the study. Unsurprisingly, $26-48 \%$ of subjects used the app to practice immediately before their assessment. As with many voluntary protocols, from medication to diet and exercise, it is difficult to maintain engagement. Motivating HCWs to partake in hand hygiene training is notoriously difficult; therefore, it is significant that the pedagogical model of self-directed learning combined with regular assessment motivated the learners and focused them on developing hand hygiene proficiency.

When we consider the current difficulties in the healthcare setting of motivating and achieving good learning outcomes in hand hygiene, this study suggests that a change of pedagogical model has the potential to improve learning outcomes and deliver efficiency benefits. Replacing a 1-h classroom session with self-directed learning followed by four weekly ward-based assessments could reduce staff time spent on hand hygiene training by $50 \%$. Each AR training session was typically $50 \mathrm{~s}$ long; this results in a mean of $20 \mathrm{~min}(\mathrm{SD}=15)$ training over 4 weeks. Each of the weekly assessments took approximately $2.5 \mathrm{~min}$, resulting in $30 \mathrm{~min}$ of learning and assessment. Furthermore, the Deliberate Practice pedagogical approach allows learners the time and incentives to develop proficiency.

Despite the size limitations, this study has demonstrated that a mobile AR training tool designed using an appropriate pedagogical model can empower learners to develop their skills independently. These initial findings suggest that healthcare organisations may improve hand hygiene quality and reduce time spent on instruction by replacing didactic classroom sessions with self-directed AR learning and regular ward-based skills assessments. 
Acknowledgements Staff and students in GCU, Sam Green \& Helga Morrow in SureWash. The Scottish Healthcare Associated Infection Prevention Institute (SHAIPI) research consortium which supports a programme of work carried out by members of the Safeguarding Health through Infection Prevention Research Group at Glasgow Caledonian University.

Author contribution GL and LP conceived of the study and, along with LG, designed the protocol. GL, JR and SC designed the app, and JR and SC implemented the design. The evaluation of the mobile app was conducted by the GCU staff (LG, KMc-K, LP) independently. GL, LG and KMc-K drafted the paper with editorial oversight from SC, JR and LP.

Funding Open Access funding provided by the IReL Consortium. No funding was provided for this research. However, SureWash provided access to the mobile AR app for all study participants and the SureWash ELITE system for assessing proficiency. SureWash has loaned two SureWash ELITE system units to LG, which she used for her PhD project.

Data availability The data in this study is the property of GCU and governed by its data protection regulations, and is not publicly accessible.

Code availability The SureWash hand Hygiene app is proprietary, but the app is free to download in the Apple and Android app stores. (software application or custom code).

\section{Declarations}

Ethical approval All staff and doctoral students from the University's Schools of Health \& Life Sciences were invited to participate in the study by email communication, including a full description of the study in the form of a participant information sheet. Participation was voluntary, but those with planned leave during the study period were excluded. Ethical approval was obtained from the Department of Nursing and Community Health Ethics Committee (HLS/NCH/17039), while access permissions were sought from the Dean of the School. Before participation, written consent was sought from all participants. For the study, each participant was randomly assigned an individual login and password for accessing the app. All data collected was identifiable only by the participants' login details so was fully anonymised.

Conflicts of interest GL, SC and JR were employees of SureWash during the development of this study. GL is an employee, and SC is a PhD student at Trinity College Dublin. GCU staff (LG, KMc-K, LP) independently evaluated the mobile AR app.

Open Access This article is licensed under a Creative Commons Attribution 4.0 International License, which permits use, sharing, adaptation, distribution and reproduction in any medium or format, as long as you give appropriate credit to the original author(s) and the source, provide a link to the Creative Commons licence, and indicate if changes were made. The images or other third party material in this article are included in the article's Creative Commons licence, unless indicated otherwise in a credit line to the material. If material is not included in the article's Creative Commons licence and your intended use is not permitted by statutory regulation or exceeds the permitted use, you will need to obtain permission directly from the copyright holder. To view a copy of this licence, visit http://creativecommons.org/licen ses/by/4.0/.

\section{References}

Higgins, A., \& Higgins, M. M. (2013). Improved hand hygiene technique and compliance in healthcare workers using gaming technology. Journal of Hospital Infection, 84(1), 32-37. https://doi. org/10.1016/j.jhin.2013.02.004 
AAPACN. (2020). Hand Hygiene Competency Tool. Retrieved the 8th of December 2020 from https:// www.aapacn.org/wp-content/uploads/2020/04/AAPACN_Hand-Hygiene-Competency-Tool_FIN. pdf

Akçayır, M., \& Akçayır, G. (2017). Advantages and challenges associated with augmented reality for education: A systematic review of the literature. Educational Research Review, 20, 1-11. https:// doi.org/10.1016/j.edurev.2016.11.002

Allegranzi, B., \& Pittet, D. (2009). Role of hand hygiene in healthcare-associated infection prevention. Journal of Hospital Infection, 73(4), 305-315. https://doi.org/10.1016/j.jhin.2009.04.019

Anderson, F., Grossman, T., Matejka, J., \& Fitzmaurice, G. (2013). YouMove: enhancing movement training with an augmented reality mirror In Proceedings of the 26th annual ACM symposium on User interface software and technology, St. Andrews https://doi.org/10.1145/2501988.2502045

Block, J. H., \& Burns, R. B. (1976). Mastery learning. Review of Research in Education, 4, 3-49.

Bloom, B. S. (1984). The 2 sigma problem: The search for methods of group instruction as effective as oneto-one tutoring. Educational Researcher, 13(6), 4-16. https://doi.org/10.3102/0013189x013006004

Blume, B. D., Ford, J. K., Baldwin, T. T., \& Huang, J. L. (2009). Transfer of training: A meta-analytic review. Journal of Management, 36(4), 1065-1105. https://doi.org/10.1177/0149206309352880

Brame, C. J. (2016). Effective educational videos: Principles and guidelines for maximizing student learning from video content. CBE-Life Sciences Education, 15(4), es6. https://doi.org/10.1187/cbe. 16-03-0125

Cannon, H. M., Feinstein, A. H., \& Friesen, D. P. (2014). Managing complexity: applying the consciouscompetence model to experiential learning. Developments in Business Simulation and Experiential Learning Vol 37: Proceedings of the Annual ABSEL Conference.

Carrier, M., \& Pashler, H. (1992). The influence of retrieval on retention. Memory \& Cognition, 20(6), 633-642. https://doi.org/10.3758/BF03202713

Chang, K.-E., Zhang, J., Huang, Y.-S., Liu, T.-C., \& Sung, Y.-T. (2019). Applying augmented reality in physical education on motor skills learning. Interactive Learning Environments. https://doi.org/10. 1080/10494820.2019.1636073

Chiu, H.-Y., Kang, Y.-N., Wang, W.-L., Tong, Y.-S., Chang, S.-W., Fong, T.-H., \& Wei, P.-L. (2020). Gender differences in the acquisition of suturing skills with the da Vinci surgical system. Journal of the Formosan Medical Association, 119(1), 462-470. https://doi.org/10.1016/j.jfma.2019.06.013

Chytas, D., Malahias, M. A., \& Nikolaou, V. S. (2019). Augmented reality in orthopedics: Current state and future directions. Front Surg, 6, 38. https://doi.org/10.3389/fsurg.2019.00038

CMS. (2019). LTC facility self-assessment tool. Centers for Medicare and Medicaid Services. Retrieved the 8th of December 2020 from https://qsep.cms.gov/data/252/A._NursingHome_InfectionControl_ Worksheet11-8-19508.pdf

Driskell, J. E., Willis, R. P., \& Copper, C. (1992). Effect of overlearning on retention. Journal of Applied Psychology, 77(5), 615.

Ericsson, K. A. (2008). Deliberate practice and acquisition of expert performance: A general overview. Academic Emergency Medicine, 15(11), 988-994. https://doi.org/10.1111/j.1553-2712.2008. 00227.x

Fischer, S., Hallschmid, M., Elsner, A. L., \& Born, J. (2002). Sleep forms memory for finger skills. Proceedings of the National Academy of Sciences, 99(18), 11987-11991. https://doi.org/10.1073/pnas. 182178199

Gerup, J., Soerensen, C. B., \& Dieckmann, P. (2020). Augmented reality and mixed reality for healthcare education beyond surgery: An integrative review. International Journal of Medical Education, 11, 1-18. https://doi.org/10.5116/ijme.5e01.eb1a

Ghosh, A., Ameling, S., Zhou, J., Lacey, G., Creamer, E., Dolan, A., ... Humphreys, H. (2013). Pilot evaluation of a ward-based automated hand hygiene training system. American Journal of Infection Control 41(4), 368-370. https://doi.org/10.1016/j.ajic.2012.03.034

Harland, T. (2003). Vygotsky's Zone of Proximal Development and Problem-based Learning: Linking a theoretical concept with practice through action research. Teaching in Higher Education, 8(2), 263-272. https://doi.org/10.1080/1356251032000052483

Jannin, L., Ganier, F., \& De Vries, P. (2019). Atomised or delayed execution? An alternative paradigm for the study of procedural learning. Journal of Educational Psychology, 111(8), 1406-1415. https:// doi.org/10.1037/edu0000357

Kardong-Edgren, S., Oermann, M. H., \& Rizzolo, M. A. (2019). Emerging theories influencing the teaching of clinical nursing skills. Journal of Continuing Education in Nursing, 50(6), 257-262. https:// doi.org/10.3928/00220124-20190516-05 
Karni, A., Meyer, G., Rey-Hipolito, C., Jezzard, P., Adams, M. M., Turner, R., \& Ungerleider, L. G. (1998). The acquisition of skilled motor performance: Fast and slow experience-driven changes in primary motor cortex. Proceedings of the National Academy of Sciences, 95(3), 861-868. https:// doi.org/10.1073/pnas.95.3.861

Khan, T., Johnston, K., \& Ophoff, J. (2019). The impact of an augmented reality application on learning motivation of students. Advances in Human-Computer Interaction, 2019, 1-14. https://doi.org/10. 1155/2019/7208494

Kneebone, R. L., Scott, W., Darzi, A., \& Horrocks, M. (2004). Simulation and clinical practice: Strengthening the relationship. Medical Education, 38(10), 1095-1102. https://doi.org/10.1111/j.1365-2929. 2004.01959.x

Kolb, D. A. (1981). Experiential learning theory and the learning style inventory: A reply to Freedman and Stumpf. Academy of Management Review, 6(2), 289-296.

Kromann, C. B., Jensen, M. L., \& Ringsted, C. (2009). The effect of testing on skills learning. Medical Education, 43(1), 21-27. https://doi.org/10.1111/j.1365-2923.2008.03245.x

Lacey, G., Showstark, M., \& Van Rhee, J. (2019). Training to Proficiency in the WHO hand hygiene technique. Journal of Medical Education and Curricular Development, 6, 2382120519867681.

Lacey, G., Zhou, J., Li, X., Craven, C., \& Gush, C. (2020). The impact of automatic video auditing with real-time feedback on the quality and quantity of handwash events in a hospital setting. American Journal of Infection Control, 48(2), 162-166.

Le, Q. T., Pedro, A., Lim, C. R., Park, H. T., Park, C. S., \& Kim, H. K. (2015). A framework for using mobile based virtual reality and augmented reality for experiential construction safety education. International Journal of Engineering Education, 31(3), 713-725.

Limbu, B., Schneider, J., Klemke, R., \& Specht, M. (2018). Augmentation of practice with expert performance data: Presenting a calligraphy use case. In Proceedings of the 3rd International Conference on Smart Learning Ecosystem and Regional Development-The Interplay of Data, Technology, Place and People, Aalborg

Llorca, D., Vilarino, F., Zhou, Z., \& Lacey, G. (2007). A multi-class SVM classifier ensemble for automatic hand washing quality assessment. In BMVC Proceeding of the British Machine Vision Conference, Warwick

Mackay, S., Morgan, P., Datta, V., Chang, A., \& Darzi, A. (2002). Practice distribution in procedural skills training. Surgical Endoscopy and Other Interventional Techniques, 16(6), 957-961.

Marky, K., Weiß, A., \& Kosch, T. (2019). supporting musical practice sessions through HMD-based augmented reality. Mensch und Computer 2019-Workshopband.

Mayer, R. E., \& Moreno, R. (2003). Nine ways to reduce cognitive load in multimedia learning. Educational Psychologist, 38(1), 43-52. https://doi.org/10.1207/S15326985EP3801_6

McLeod, P. J., Steinert, Y., Trudel, J., \& Gottesman, R. (2001). Seven principles for teaching procedural and technical skills. Academic Medicine, 76(10), 1080.

Mladenovic, R., Pereira, L. A. P., Mladenovic, K., Videnovic, N., Bukumiric, Z., \& Mladenovic, J. (2019). Effectiveness of augmented reality mobile simulator in teaching local anesthesia of inferior alveolar nerve block. Journal of Dental Education, 83(4), 423-428. https://doi.org/10.21815/JDE. 019.050

Moulton, C. A., Dubrowski, A., Macrae, H., Graham, B., Grober, E., \& Reznick, R. (2006). Teaching surgical skills: What kind of practice makes perfect?: A randomised, controlled trial. Annals of Surgery, 244(3), 400-409. https://doi.org/10.1097/01.sla.0000234808.85789.6a

Mylon, P., Lewis, R., Carré, M. J., \& Martin, N. (2016). An evaluation of dexterity and cutaneous sensibility tests for use with medical gloves. Proceedings of the Institution of Mechanical Engineers, Part C, 230(16), 2896-2912.

Okimoto, M. L. L. R., Okimoto, P. C., \& Goldbach, C. E. (2015). User experience in augmented reality applied to the welding education. Procedia Manufacturing, 3, 6223-6227. https://doi.org/10.1016/j. promfg.2015.07.739

Persky, A. M., \& McLaughlin, J. E. (2017). The flipped classroom-from theory to practice in health professional education. American Journal of Pharmaceutical Education, 81(6), 118. https://doi.org/ 10.5688/ajpe 816118

Reed, T., Pirotte, M., McHugh, M., Oh, L., Lovett, S., Hoyt, A. E., ... McGaghie, W. C. (2016). Simulation-based mastery learning improves medical student performance and retention of core clinical skills. Simulation in Healthcare, 11(3), 173-180. https://doi.org/10.1097/sih.0000000000000154 
Rikers, R. M. J. P., Van Gerven, P. W. M., \& Schmidt, H. G. (2004). Cognitive load theory as a tool for expertise development. Instructional Science, 32(1), 173-182. https://doi.org/10.1023/B:TRUC. 0000021807.49315 .31

Roediger, H. L., \& Karpicke, J. D. (2006). Test-enhanced learning: Taking memory tests improves longterm retention. Psychological Science, 17(3), 249-255. https://doi.org/10.1111/j.1467-9280.2006. 01693.x

Salem, S., Cooper, J., Schneider, J., Croft, H., \& Munro, I. (2020). Student acceptance of using augmented reality applications for learning in pharmacy: A pilot study. Pharmacy (basel). https://doi. org/10.3390/pharmacy8030122

SA_Health. (2020). Hand Hygiene Competency Tool. Retrieved the 8th of December 2020 from https:// www.sahealth.sa.gov.au/wps/wcm/connect/229ba98045d6566c8396cb574adac1f8/HH-competencytool_v2.6+\%28Jan2020\%29.pdf?MOD=AJPERES\&CACHEID=ROOTWORKSPACE-229ba 98045d6566c8396cb574adac1f8-niRDJoP.

Schott, C. K., Kode, K. R., \& Mader, M. J. (2020). Teaching vs learning: Impact of deliberate practice and formative feedback on developing point of care ultrasound skills. Journal of Clinical Ultrasound, 48(8), 437-442. https://doi.org/10.1002/jcu.22878

Slijepcevic, N. (2013). The effect of augmented reality treatment on learning, cognitive load, and spatial visualization abilities. Ph.D. Dissertation, University of Kentucky.

Stewardson, A. J., Iten, A., Camus, V., Gayet-Ageron, A., Caulfield, D., Lacey, G., \& Pittet, D. (2014). Efficacy of a new educational tool to improve Handrubbing technique amongst healthcare workers: A controlled, before-after study. PLOS ONE, 9(9), e105866. https://doi.org/10.1371/journal.pone. 0105866

SureWash. (2021). SureWash Hand Hygiene App. Retrieved the 8th of December 2020 from https://surew ash.com/surewash-app-practice-hand-hygiene/.

Sutter, S. T., Frei, R., Dangel, M., \& Widmer, A. F. (2010). Effect of teaching recommended World Health Organization technique on the use of alcohol-based hand rub by medical students. Infection Control \& Hospital Epidemiology, 31(11), 1194-1195. https://doi.org/10.1086/656745

Tiffin, J. (1968). Purdue pegboard examiner manual. Chicago: Science Research Associates.

Tiffin, J., \& Asher, E. J. (1948). The Purdue Pegboard: Norms and studies of reliability and validity. Journal of Applied Psychology, 32(3), 234.

Tonhäuser, C., \& Büker, L. (2016). Determinants of transfer of training: A comprehensive literature review. International Journal for Research in Vocational Education and Training, 3(2), 127-165. https://doi.org/10.13152/ijrvet.3.2.4

Tschudin-Sutter, S., Sepulcri, D., Dangel, M., Schuhmacher, H., \& Widmer, A. F. (2015). Compliance with the World Health Organization hand hygiene technique: A prospective observational study. Infection Control and Hospital Epidemiology, 36(4), 482-483. https://doi.org/10.1017/ice.2014.82

Tseng, Y.-C., Chang, K.-Y., Liu, P.-L., \& Chang, C.-C. (2017). Applying the purdue pegboard to evaluate precision assembly performance. In 2017 IEEE International Conference on Industrial Engineering and Engineering Management (IEEM),

Turner, J. L., \& Dankoski, M. E. (2008). Objective structured clinical exams: A critical review. Family Medicine, 40(8), 574-578.

WHO. (2009). WHO guidelines on hand hygiene in health care: First global patient safety challenge clean care is safer care. In WHO Guidelines on Hand Hygiene in Health Care: First Global Patient Safety Challenge Clean Care Is Safer Care. World Health Organization Press.

Widmer, A. F., Conzelmann, M., Tomic, M., Frei, R., \& Stranden, A. M. (2007). Introducing alcoholbased hand rub for hand hygiene: The critical need for training. Infection Control and Hospital Epidemiology, 28(1), 50-54. https://doi.org/10.1086/510788

Wisher, R. A. (1992). the role of complexity on retention of psychomotor and procedural skills. Proceedings of the Human Factors Society Annual Meeting, 36(15), 1171-1175. https://doi.org/10.1518/ 107118192786749676

Zhu, E., Hadadgar, A., Masiello, I., \& Zary, N. (2014). Augmented reality in healthcare education: An integrative review. PeerJ, 2, e469. https://doi.org/10.7717/peerj.469

Publisher's note Springer Nature remains neutral with regard to jurisdictional claims in published maps and institutional affiliations. 